\title{
Body mass index reference curves for the UK, 1990
}

\author{
T J Cole, J V Freeman, M A Preece
}

\begin{abstract}
Reference curves for stature and weight in British children have been available for the past 30 years, and have recently been updated. However weight by itself is a poor indicator of fatness or obesity, and there has never been a corresponding set of reference curves to assess weight for height. Body mass index (BMI) or weight/height ${ }^{2}$ has been popular for assessing obesity in adults for many years, but its use in children has developed only recently. Here centile curves for BMI in British children are presented, from birth to 23 years, based on the same large representative sample as used to update the stature and weight references. The charts were derived using Cole's LMS method, which adjusts the BMI distribution for skewness and allows BMI in individual subjects to be expressed as an exact centile or SD score. Use of the charts in clinical practice is aided by the provision of nine centiles, where the two extremes identify the fattest and thinnest four per 1000 of the population.

(Arch Dis Child 1995; 73: 25-29)
\end{abstract}

Keywords: body mass index, growth reference, overweight, underweight.

New reference growth curves for the UK have recently been published, ${ }^{1}$ allowing the attained heights and weights of British children to be assessed relative to centiles based on recently collected and nationally representative data. They replace the Tanner-Whitehouse reference curves, which are now 30 years old.

A longstanding deficiency of reference curves for the UK (and indeed other Western nations) has been their inability to assess child fatness. Weight and height are highly correlated during childhood, so that a child's weight centile tends to be strongly influenced by his or her height centile. Both are a reflection primarily of the child's size (large versus small) rather than their shape (fat versus thin).

Weight adjusted for height provides a simple measure of fatness, and many weight for height indices have been proposed for the purpose. ${ }^{2}$ The American National Center for Health Statistics (NCHS) growth reference included child weight for height charts, but they covered the restricted age range from birth to 10 years in girls and 11.5 years in boys, and omitted adolescence entirely. ${ }^{3}$ A problem with weight for height charts is that they fail to adjust for age in early life, so that short toddlers are compared with tall infants, periods of life when the body fat content differs substantially. ${ }^{45}$
Another weight for height index suitable for the age group 4-12 years has been proposed by Chinn $e t a l,{ }^{6}$ based on its correlation with skinfold thickness. Defined as (weight (kg)-9)/ height $(\mathrm{cm})^{3 \cdot 7}$, it has the dual properties that its mean and coefficient of variation are both unrelated to age. This means that it does not need adjusting for age.

A very flexible index of overweight is provided by the power function weight/height ${ }^{n}$, where $\mathrm{n}$ the power of height usually takes values in the range 1 to 3 . Restricting it to whole numbers, the value for $\mathrm{n}$ which best adjusts weight for height, and at the same time removes most of the trend of increasing weight with age, is $n=2 .{ }^{78}$ This leads to the body mass index (BMI) weight/height ${ }^{2}$, also known as the Quetelet index ${ }^{9}$ or the Kaup index. ${ }^{10}$

BMI has been used widely in adults for the last 25 years as a simple summary measure of overweight, ${ }^{11} 12$ but its use in childhood has developed relatively recently. Adult BMI increases fairly slowly with age, so that age independent cut offs can be used to grade obesity. ${ }^{13}$ In children, however, BMI changes substantially with age, rising steeply in infancy, falling during the preschool years, and then rising again into adulthood. For this reason, child BMI needs to be assessed using age related reference curves.

Such curves have been published for French $^{814}$ and American ${ }^{1516}$ children, but they are all imperfect, either because the data are old or the age range is restricted. This paper provides up-to-date reference curves for BMI in UK children, covering the age range birth to 23 years, and presented as nine centiles. They are among the first such curves to complement existing national references for weight and height based on the same dataset.

\section{Methods}

SUBJECTS

The reference sample of children was obtained by combining data from 11 distinct surveys. Table 1 summarises the separate studies, and more details are given in the publication describing the stature and weight references. ${ }^{1}$ The HUMAG surveys were carried out by the Human Measurements Anthropometry and Growth Research Group at Loughborough University. All except the Tayside, Cambridge, and Whittington Hospital samples were representative of England, Scotland and (mostly) Wales, while for all except the Cambridge study, the data were cross sectional. The Cambridge sample included longitudinal data collected at 15 ages between 4 weeks and 2 years. 
Table 1 Details of the studies providing data

\begin{tabular}{llllr}
\hline Study & Date & Ages (years) & Region $^{\star}$ & Sample size \\
\hline HUMAG & & & & \\
$\quad$ Infants & 1987 & $0-<2$ & E, W & 789 \\
Toddlers & 1987 & $2-<5$ & E, W & 1014 \\
Boys & 1978 & $5-<17$ & E, S & 3498 \\
Girls & 1986 & $5-<16$ & E, S, W & 4280 \\
Men & 1984 & $16-<23$ & E, S, W & 1748 \\
Women & 1987 & $16-<23$ & E, S, W & 1057 \\
NSHG & $1989-90$ & $4 \cdot 5-<12$ & E, S & 10495 \\
Department of Health & 1980 & $16-<23$ & E, S, W & 1413 \\
Tayside Growth Study & $1989-90$ & $4 \cdot 5-<14$ & S & 1622 \\
Whittington Hospital & $1987-8$ & $33-42$ weeks' gestation & E & 756 \\
Cambridge Infant Growth & $1984-90$ & 4 weeks -2 years & E & 3863 \\
$\quad$ Study & & & & \\
\hline
\end{tabular}

${ }^{\star} \mathrm{E}=$ England, $\mathrm{S}=$ Scotland, $\mathrm{W}=\mathrm{W}$ ales .

DATA

All the surveys collected data on sex, age, height, and weight. Weight was measured either in underclothes or adjusted for clothing weight, while height was measured with the head held in the Frankfort plane. In those under 2 years, length rather than height was obtained. Exact decimal age was calculated from the dates of birth and measurement.

\section{STATISTICAL METHODS}

The data were collected between 1978 and 1990 , a long enough period of time for there to be a possible secular trend present. There were also methodological differences in the study protocols. To minimise these effects, the weights and heights for each study were adjusted up or down by a constant percentage (taking age and geographic area into account), to make the studies as similar as possible, using the National Study of Health and Growth (NSHG) as the baseline (NSHG was chosen because of its size and recent date). BMI was then calculated from adjusted weight and height, with units $\mathrm{kg} / \mathrm{m}^{2}$. The analyses were done for the sexes separately.

Summary centile curves were fitted to the data using the LMS method and penalised likelihood. ${ }^{17}$ In brief, the LMS method

Table 2 Numbers of child measurements, by age and sex

\begin{tabular}{crr}
\hline Age group (years) & \multicolumn{1}{c}{ Male } & Female \\
\hline$<35$ weeks & 3 & 2 \\
$35-39$ weeks & 154 & 139 \\
$0+$ & 712 & 662 \\
$0 \cdot 25+$ & 482 & 421 \\
$0 \cdot 50+$ & 461 & 419 \\
$0 \cdot 75+$ & 462 & 407 \\
$1+$ & 305 & 276 \\
$1 \cdot 5+$ & 208 & 193 \\
$2+$ & 202 & 204 \\
$3+$ & 176 & 164 \\
$4+$ & 349 & 337 \\
$5+$ & 1143 & 1264 \\
$6+$ & 1159 & 1130 \\
$7+$ & 1240 & 1200 \\
$8+$ & 1208 & 1183 \\
$9+$ & 1261 & 1201 \\
$10+$ & 1223 & 1113 \\
$11+$ & 925 & 831 \\
$12+$ & 354 & 387 \\
$13+$ & 337 & 414 \\
$14+$ & 430 & 541 \\
$15+$ & 291 & 410 \\
$16+$ & 499 & 389 \\
$17+$ & 407 & 308 \\
$18+$ & 416 & 267 \\
$19+$ & 404 & 282 \\
$20+$ & 382 & 253 \\
$21+$ & 233 & 253 \\
$22+$ & 210 & 249 \\
Total & 15636 & 14899 \\
\hline & &
\end{tabular}

summarises the distribution of BMI at each age by its median $(M)$ and coefficient of variation (S), plus a measure of skewness based on the Box-Cox power (L) required to transform the data to normality. These three quantities depend on age, and are represented by smooth curves plotted against age. In particular the $M$ curve is the 50th centile curve for BMI.

Curves for other centiles are obtained using the formula:

$$
\mathrm{C}_{100 \alpha}(\mathrm{t})=\mathrm{M}(\mathrm{t})\left[1+\mathrm{L}(\mathrm{t}) \mathrm{S}(\mathrm{t}) \mathrm{z}_{\alpha}\right]^{1 / L(t)}
$$

where $z_{\alpha}$ is the normal equivalent deviate for tail area $\alpha, \mathrm{C}_{100 \alpha}$ is the BMI centile corresponding to $z_{\alpha}$ (for example for the 25 th centile, $\alpha=0.25$ and $\left.z_{\alpha}=-0.67\right), t$ is age in years, and $\mathrm{L}(\mathrm{t}), \mathrm{M}(\mathrm{t}), \mathrm{S}(\mathrm{t})$, and $\mathrm{C}_{100 \alpha}(\mathrm{t})$ indicate the corresponding values of each curve at age $t$.

A bonus of the LMS method is that knowing the $\mathrm{L}, \mathrm{M}$ and $\mathrm{S}$ curves, it is straightforward to produce curves for any required BMI centile, simply by choosing $z_{\alpha}$ appropriately in (1). Also, by rearranging equation (1), it is possible to convert a child's BMI to an exact SD score as follows:

$$
\mathrm{SD} \text { score }=\frac{[\mathrm{BMI} / \mathrm{M}(\mathrm{t})]^{\mathrm{L}(\mathrm{t})}-1}{\mathrm{~L}(\mathrm{t}) \mathrm{S}(\mathrm{t})}
$$

where $L(t), M(t)$, and $S(t)$ are the values of $L$, $M$, and $S$ suitable for the child's age and sex. The SD score can if required be converted to a centile, using normal distribution tables (the SD score and centile are in the same relationship as $z_{\alpha}$ and $100_{\alpha}$ in equation (1)).

\section{Results}

The dataset consists of BMI for 15636 boys and 14899 girls, for ages between 33 weeks of gestation and 23 years. The age-sex distribution of the measurements is given in table 2 . Figures 1 and 2 give BMI reference centile curves for boys and girls in the nine centile format of Cole. ${ }^{18}$ This is the format used for the published height and weight reference curves, ${ }^{1}$ except that their upper age limit is 20 years. The central seven centiles are similar to the conventional 3rd, 10th, 25th, 50th, 75th, 90th and 97th, while the extra centiles in each tail define the largest and smallest $0.4 \%$ of the population. Note that the centiles are very skew, with the top centile channel in the two figures over four times as wide as the bottom centile channel at all ages.

The changes in median BMI by age are on the whole very similar in the two sexes. BMI increases steeply in early life, from $10.6 \mathrm{~kg} / \mathrm{m}^{2}$ at 35 weeks of gestation, to 14.0 at 42 weeks, and a peak of $17 \cdot 6$ at 8 months. Subsequently it declines, and then flattens out at 5.5 years when BMI is $15.5 \mathrm{~kg} / \mathrm{m}^{2}$. This dip in the BMI is called the adiposity rebound. ${ }^{19}$ The age at adiposity rebound is later on the lower than the higher centiles (figs 1 and 2), by over three years in boys and two years in girls. In infancy all the centiles peak at the same age. After the rebound BMI increases more rapidly in girls than in boys, but at 18 , when median BMI is $21 \cdot 0$, the curves cross and subsequently boys' $\mathrm{BMI}$ is higher. 


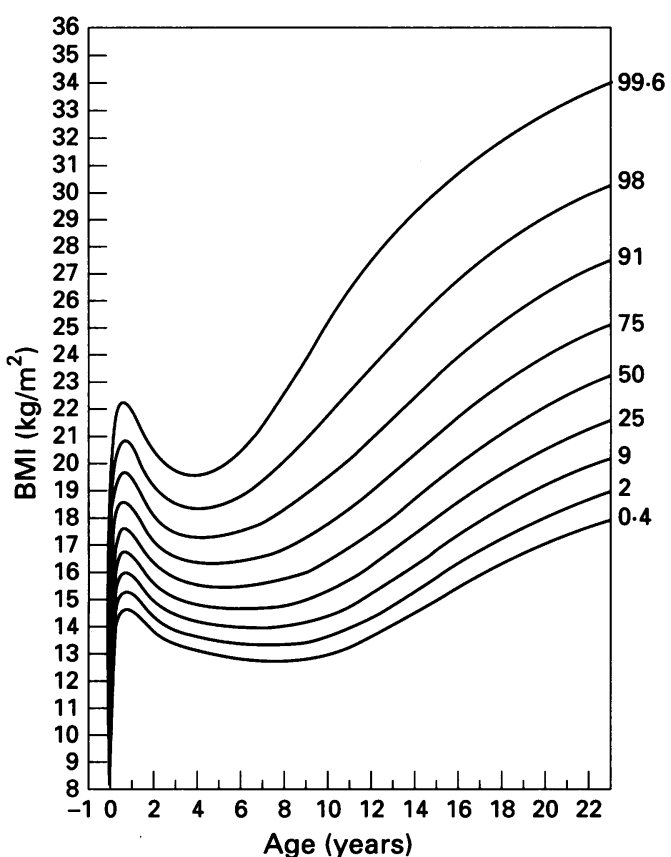

Figure 1 Nine centiles for BMI in British boys 1990. The centiles are spaced two thirds of an SD score apart.

Figures 3 and 4 show respectively the $S$ curves and $\mathrm{L}$ curves of BMI by sex. The $S$ curve (fig 3) defines the coefficient of variation of BMI, shown here multiplied by 100 to make it a percentage. The variability is about $10 \%$ in infancy, falling to below $8 \%$ and then rising to a peak of $12-13 \%$ in adolescence. The rise occurs two years earlier in girls, reflecting the timing of the adolescent growth spurt in the two sexes. Subsequently the variability falls slightly.

The L curves (fig 4) measure the skewness of the BMI distribution, a value of 1 indicating normality and smaller values representing progressively greater skewness. At birth BMI is already somewhat skew, but during the first

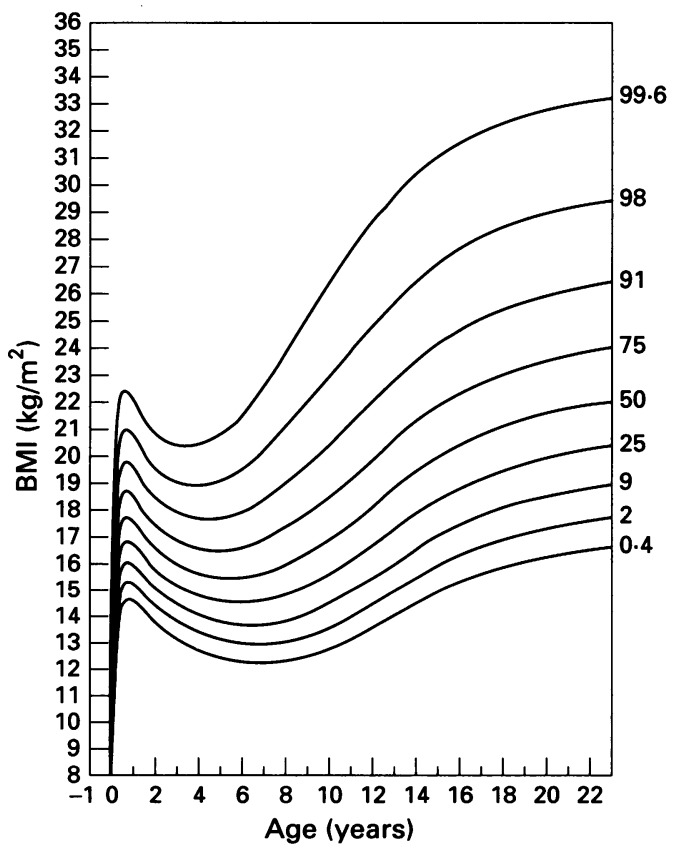

Figure 2 Nine centiles for BMI in British girls 1990. The centiles are spaced two thirds of an SD score apart.

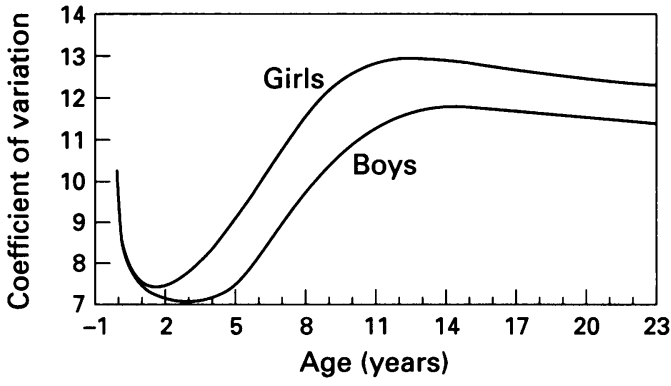

Figure 3 Coefficient of variation (S curve) of BMI in British boys and girls.

year when BMI rises steeply, the degree of skewness also increases sharply. Subsequently it changes little. This degree of skewness is far greater than for weight, and is reflected in the spacing of the BMI centiles (figs 1 and 2).

\section{Discussion}

For the first time, centiles of BMI as well as weight and height are available for British children, covering the whole of childhood from birth to 23 years, and based on recently collated and nationally representative data. The centiles are similar in general shape to those published for French and American children, but the centiles are slightly higher than the French centiles (though not those from the USA). This may reflect the more recent provenance of the UK information, the French charts being based primarily on data from the French longitudinal growth study, ${ }^{20}$ children born between 1953 and 1960. The data thus correspond to a measurement period of the 1970 s, since which time the prevalence of both child and adult obesity has increased greatly. ${ }^{21} 22$

Because they have not long been available, child BMI charts are relatively untried in clinical practice. They can be used to identify children who are unusually fat or thin on the basis of a single measurement, and the extra centiles at the top and bottom of the chart are useful for this. Just eight children per 1000 lie outside the nine centile range, four above and four below, and thus they represent an extreme group. The published charts for height and weight recommend that children whose measurements fall in this region should be referred immediately, and the same probably should apply to BMI as well. However more experience of the charts is needed.

The way the charts are constructed allows individual BMI measurements to be converted

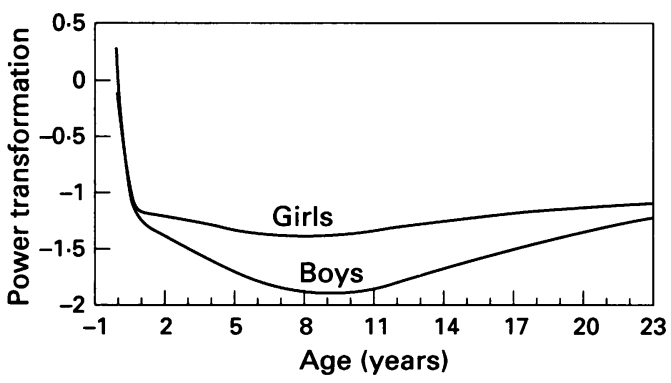

Figure 4 Degree of skewness ( $L$ curve) of BMI in British boys and girls. 
to an exact SD score. As an example take an obese girl aged 11 years, with a BMI of 29 $\mathrm{kg} / \mathrm{m}^{2}$. At age 11 the values of $L$ and $S$ are -1.3 and $13 \%$ respectively (figs 3 and 4 ), while $M$ the median $B M I$ is 17.5 (fig 2). Putting these values into equation (2) gives:

$$
\begin{aligned}
\text { SD score } & =\frac{[29 / 17.5]^{-1.3}-1}{-1.3 \times 13 / 100} \\
& =2.85
\end{aligned}
$$

which is on the $99 \cdot 8$ th centile and hence appreciably above the top line on the chart. BMIs as extreme as this are not very useful expressed as centiles, being so close to $100 \%$.

In fact this equation can be simplified. After the age of 18 months, the value of $L$ in fig 4 is fairly close to -1 in both sexes, indicating that something like a reciprocal transformation is needed to make BMI normally distributed. The reciprocal of $\mathrm{BMI}$ is height ${ }^{2} /$ weight, so this is a better simple index to work with if normality is important. To calculate its SD score, equation (2) can be simplified by setting $\mathrm{L}$ to -1 , giving:

$$
\mathrm{SD} \text { score }=\frac{1-[\mathrm{M}(\mathrm{t}) / \mathrm{BMI}]}{\mathrm{S}(\mathrm{t})}
$$

Applying this to the example of the obese girl gives:

$$
\begin{aligned}
\text { SD score } & =\frac{1-[17 \cdot 5 / 29]}{13 / 100} \\
& =3.05
\end{aligned}
$$

which is similar to the exact SD score based on equation (2). So equation (3) can be used to obtain an approximate SD score for BMI in children over 18 months old.

During infancy median BMI increases dramatically, from around $10 \mathrm{~kg} / \mathrm{m}^{2}$ at 35 weeks' gestation to a peak of 17 or more at 8 months. It is important for obstetricians wanting to use BMI with neonates to adjust it for age, since it increases by over $30 \%$ between 35 and 42 weeks of gestation.

There is little evidence that infant BMI is predictive of $\mathrm{BMI}$ later, ${ }^{23}$ and slight differences in the timing of its rise and subsequent fall can lead to marked centile crossing. For this reason BMI is likely to be particularly difficult to interpret in infancy, and infants on extreme centiles should be viewed conservatively. Only if the pattern persists well into the second year should it be considered clinically important.

More useful for predicting later obesity are serial measurements of BMI between the ages of 3 and 8 years. Rolland-Cachera and colleagues have shown that most children follow the pattern of the BMI chart, with a fall then a rise in $\mathrm{BMI}$ during this period. ${ }^{19} 24$ The timing of the low point, the age of adiposity rebound, is diagnostic of later fatness - the earlier the adiposity rebound the greater the risk of adult obesity. Although the current BMI centiles are based on cross sectional rather than longitudinal data, it is striking that the lower centiles have their rebound later, by three years or more, than the higher centiles. Hammer et al have made the same observation. ${ }^{15}$ This reinforces the idea that the age when a child's BMI rebounds is just as important as the BMI value at that age.
It is customary with adults to use a fixed BMI cut off to define obesity, and various cut offs between 25 and 30 have been suggested, for example by Garrow. ${ }^{13}$ Many use as their rationale the link between obesity and mortality, so that those above the cut off are at demonstrably increased risk. However this argument does not apply to children, as the data linking child obesity and later mortality are sparse, and in any case the association between them may be too weak to be predictive. It makes better sense to treat child BMI as an anthropometric measure and express it as an SD score or centile. This avoids the need to relate child obesity to later mortality, at least until better data are available.

It is striking that the 98 th centile at age 20 is $29.0 \mathrm{~kg} / \mathrm{m}^{2}$ for both sexes, similar to the cut offs proposed for adults, whereas the 99.6 th centile is $32 \cdot 8$. These centiles seem to be reasonable definitions of child obesity and superobesity respectively.

In conclusion, these BMI charts, taken in conjunction with those for height and weight, provide the means to monitor both the size and shape of the UK child population.

The authors are grateful to Sue Chinn (NSHG, UMDS), Gaye Henson (Whittington Hospital), Peter Jones (HUMAG), Elizabeth White (Tayside Growth Study), and Roger Whitehead (Cambridge Infant Growth Study) for making their data available. Peter Davies provided valuable comments on earlier drafts of the paper.

Copies of the BMI charts can be obtained through the Child Growth Foundation, 2 Mayfield Avenue, London W4 1PW. A diskette containing the age-sex specific values of $L, M$, and $S$ for stature, weight, and BMI can be obtained from the same source.

1 Freeman JV, Cole TJ, Chinn S, Jones PRM, White EM, Preece MA. Cross sectional stature and weight reference curves for the UK, 1990. Arch Dis Child 1995; 73: 17-24.

2 Cole TJ. Weight-stature indices to measure underweight overweight and obesity. In: Himes JH, ed. Anthropometric overweight and obesity. In: Himes $\mathrm{JH}$, ed. Anthropometric assessment of nuth

3 Hamill PVV, Drizd TA, Johnson CL, Reed RB, Roche AF. NCHS growth curves for children birth - 18 years. Washington DC: National Center for Health Statistics, 1977 Vital and Health Statistics Series 11: No 165

4 Fomon SJ, Haschke F, Ziegler EE, Nelson SE. Body composition of reference children from birth to age 10 years. Am $\mathcal{F}$ Clin Nutr 1982; 35: 1169-75.

5 Cole TJ. A critique of the NCHS weight for height standard. Hum Biol 1985; 57: 183-96.

6 Chinn S, Rona RJ, Gulliford MC, Hammond J. Weight-forheight in children aged 4-12 years. A new index compared to the normalized body mass index. Eur $f$ Clin Nutr 1992; 46: 489-500.

7 Cole TJ. A method for assessing age-standardized weightfor-height in children seen cross-sectionally. Ann Hum Biol 1979; 6: 249-68.

8 Rolland-Cachera MF, Sempé M, Guilloud-Bataille $M$, Patois E, Pequignot-Guggenbuhl F, Fautrad V. Adiposity indices in children. Am $\mathcal{f}$ Clin Nutr 1982; 36: 178-84.

9 Quetelet LAJ. Physique sociale. Vol 2. Brussels: C Muquardt, 1869

10 Kaup J. Ein korperproportionsgesetz zur beurteilung der langegewichtsund index-abweicher populations-altergruppe. Munchener Medizinische Wochenschrift 1921; 68: 976-8.

11 Khosla T, Lowe CR. Indices of obesity derived from body weight and height. British fournal of Preventive and Sociol Medicine 1967; 21: 122-8.

12 Garrow JS, Webster J. Quetelet's index $\left(\mathrm{W} / \mathrm{H}^{2}\right)$ as a measure of fatness. Int $\mathcal{F}$ Obes 1985; 9: 147-53.

13 Garrow JS. Treat obesity seriously: a clinical manual. London Churchill Livingstone, 1981

14 Rolland-Cachera MF, Cole TJ, Sempé M, Tichet J, Rossignol C, Charraud A. Body mass index variations centiles from birth to 87 years. Eur $\mathcal{f}$ Clin Nutr 1991; 45: 13-21.

15 Hammer LD, Kraemer HC, Wilson DM, Ritter PL Dornbusch SM. Standardized percentile curves of body mass index for children and adolescents. Am $₹$ Dis Child mass index for child

16 Must A, Dallal GE, Dietz WH. Reference data for obesity: 85th and 95 th percentiles of body mass index $\left(w t / h t^{2}\right)$ and 85th and 95th percentiles of body mass index $\left(w t / t^{2}\right)$ and
triceps skinfold thickness. Am $f$ Clin Nutr 1991; 53: 839-46. 17 Cole TJ, Green PJ. Smoothing reference centile curves: the 
LMS method and penalized likelihood. Stat Med 1992; 11: 1305-19.

18 Cole TJ. Do growth chart centiles need a facelift? $B M F$ 1994; 308: 641-2.

19 Rolland-Cachera MF, Deheeger M, Bellisle F, Sempé M, Guilloud-Bataille $M$, Patois E. Adiposity rebound in children: a simple indicator
Clin Nutr 1984; 39: 129-35.

20 Sempé M, Pédron G, Roy-Pernot M. Auxologie: méthode et séquences. Paris: Theraplix, 1979

21 Peckham CS, Stark O, Simonite V, Wolff OH. Prevalence of obesity in British children born in 1946 and 1958. BMF 1983; 286: 1237-42.

22 Gulliford MC, Rona RJ, Chinn S. Trends in body mass index in young adults in England and Scotland from 1973 index in young adults in England and Scotland from 1973 23 Poskitt EME, Cole TJ. Do fat babies stay fat? BMF 1977; i: 7-9.

24 Rolland-Cachera MF, Deheeger M, Guilloud-Bataille $M$, Avons P, Patois E, Sempé M. Tracking the development of adiposity from one month of age to adulthood. $A n n$ Hum Biol 1987; 14: 219-29.

\section{Parents, children, and eating}

There may be an innate regulatory mechanism that allows children to control their own energy intake. The malfunction of such a mechanism, known as caloric compensation, could explain obesity in some children. Workers in Illinois (Susan L Johnson and Leann L Birch, Pediatrics 1994; 94: 653-61) have studied this mechanism and the factors which affect it.

Seventy seven children aged 2 to 4 years attending a day care nursery were studied. They were given a standard amount (163 g) of either a high energy ( $150 \mathrm{kcal}(625 \mathrm{~kJ}$ ) per serving) or a low energy ( $3 \mathrm{kcal}(13 \mathrm{~kJ})$ ) drink and then allowed to eat as much lunch as they wished. The drinks were said to be indistinguishable and differed only in energy content. Half of the children received the high energy drink and half the low, but two days later the procedure was repeated with each child receiving the alternative drink. The energy contents of the lunches were calculated and a calorie compensation index (COMPX) calculated as the extra calories taken after being given the low energy drink expressed as a percentage of the energy difference between the two drinks. Questionnaires were used to assess parents' attitudes to their own food intakes and to the feeding of their children. The children's height, weight, and skinfold thicknesses were measured and parents were asked their own height and weight.

On average the children compensated for $46 \%$ of the energy difference (mean (SEM) COMPX $=46 \cdot 2(5 \cdot 7)$ ), but there was very wide variation, from $-80 \%$ to $+230 \%$. Boys compensated better (COMPX 57.1 (9.5)) than girls (36.0 (6.8)). Twenty eight children were tested again one year later and the COMPX was found to be relatively stable $(r=0.42, p<0.001)$. Children with the lowest COMPX scores were significantly fatter than those with the highest scores. In girls there was a significant negative correlation between COMPX scores and body fat. Boys, on the whole, were leaner than girls and in them there was a significant positive correlation between COMPX scores and lean body mass. Parents whose questionnaire responses showed them to attempt to exert a high degree of control over their children's eating had children who were less able to control their own energy intake ('parent control index' was strongly negatively correlated with children's COMPX; $r=0.65, \mathrm{p}<0.0001$ ). Parents who reported disinhibition in their own eating had children with lower caloric compensation and mothers who made a habit of dieting had girls, but not boys, with low COMPX scores.

Parents almost certainly act as role models for their children's eating patterns and there may also be genetic factors involved in the regulation of energy intake. American mothers may be more likely to attempt to control their daughters' food intake than their sons'. Whether this applies to mothers in other countries seems uncertain.

Much of a paediatrician's life is spent trying to reassure parents about their toddler's apparently low food intake and advising against food forcing. This study adds weight to the concept that parental attempts to regulate children's food intake are likely to be counterproductive and suggests that they may actively impair the children's ability to regulate their own energy intake. 